\title{
新型光伏储电原位集成电池研究进展
}

\author{
于守武 ${ }^{1}$, 赵泽文 ${ }^{1,2}$, 赵晋津 ${ }^{2}$, 肖淑娟 ${ }^{1}$, 师 岩 $^{3}$, 高存法 ${ }^{3}$, \\ 苏 晓 ${ }^{2}$, 胡宇翔 ${ }^{4}$, 赵智胜 ${ }^{5}$, 王 婕 ${ }^{2}$, 王连洲 4
}

(1. 华北理工大学 材料科学与工程学院, 唐山 063009 ; 2. 石家庄铁道大学 材料科学与工程学院, 石家庄 050043 ; 3. 南京航空航天大学 机械结构强度与振动国家重点实验室, 南京 210016; 4. 昆士兰大学 化工学院, 纳米材料研 究中心, 澳大利亚生物工程与纳米科技研究所, 布里斯班 QLD 4072, 澳大利亚; 5. 燕山大学 亚稳材料制备技术 与科学国家重点实验室, 秦皇岛 066004)

摘 要: 随着光伏智能电子产品日益融入到日常生活, 人们不仅对高性能光伏发电设备的需求增加, 同时对智能 化、可持续和快速充电/放电能源集成设备的需求也急剧增加, 将能量产生部件和能量存储部件结合成独立设备已 经成为一种极具有吸引力和挑战性的前沿技术。原位逐层制备光电转换功能薄膜与储电功能薄膜并组装, 获得光伏 储电原位集成电池的技术, 既减少了太阳光波动对能量输出的影响, 又可以实现光伏自供电、弱光缓冲和可穿戴等 功能, 因此具有良好的发展前景。本文综述了硅基光伏储电原位集成电池、敏化光伏储电原位集成电池、钙钛矿光 伏储电原位集成电池的最新研究成果, 介绍了此类新型电池性能的评价方法, 分析了其工作原理、构造特点和性能 参数, 并对此新兴研究领域的发展趋势进行了展望。

关 键 词: 硅基太阳能电池; 敏化太阳能电池; 钲钛矿太阳能电池; 能量储存; 光伏储能; 原位集成; 综述 中图分类号: TQ174 文献标识码: A

\section{Research Progress in Novel In-situ Integrative Photovoltaic-storage Tandem Cells}

\author{
YU Shouwu $^{1}$, ZHAO Zewen ${ }^{1,2}$, ZHAO Jinjin ${ }^{2}$, XIAO Shujuan ${ }^{1}$, SHI Yan ${ }^{3}$, GAO Cunfa ${ }^{3}$, \\ SU Xiao $^{2}$, HU Yuxiang ${ }^{4}$, ZHAO Zhisheng $^{5}$, WANG Jie ${ }^{2}$, WANG Lianzhou ${ }^{4}$
}

(1. College of Materials Science and Engineering, North China University of Science and Technology, Tangshan 063009, China; 2. School of Materials Science and Engineering, Shijiazhuang Tiedao University, Shijiazhuang 050043, China; 3. State Key Laboratory of Mechanics and Control of Mechanical Structures, Nanjing University of Aeronautics and Astronautics, Nanjing 210016, China; 4. Australian Institute for Bioengineering and Nanotechnology, Nanomaterials Centre, School of Chemical Engineering, The University of Queensland, Brisbane QLD 4072, Australia; 5. State Key Laboratory of Metastable Materials Science and Technology, Yanshan University, Qinhuangdao 066004, China)

Abstract: As smart electronic products are increasingly applied in our daily life, there is not only an increasing demand for high-performance photovoltaic power generation devices, but also strong need for in-situ energy storage functions in these devices. The integration of energy generating components and energy storage components into one

收稿日期：2019-07-10；收到修改稿日期：2019-09-01

基金项目: 河北省自然科学基金杰出青年项目(A2019210204); 国家自然科学基金(11772207); 河北省青年拔尖人才支持计 划; 深圳孔雀团队计划(KQTD20170810160424889); 机械结构力学及控制国家重点实验室(南京航空航天大学) 开放课题(MCMS-E-0519G04); 亚稳材料制备技术与科学国家重点实验室(燕山大学)开放基金(201919) Natural Science Foundation of Hebei Province for Distinguished Young Scholar (A2019210204); National Natural Science Foundation of China(11772207); Youth Top-notch Talents Supporting Plan of Hebei Province; Shenzhen Peacock Team Program (KQTD20170810160424889); State Key Laboratory of Mechanics and Control of Mechanical Structures, Nanjing University of Aeronautics and Astronautics (MCMS-E-0519G04); The Open Fund of State Key Laboratory of Metastable Materials Science and Technology (201919)

作者简介: 于守武(1979-), 男, 博士, 副教授. E-mail: yushouwu@ncst.edu.cn YU Shouwu (1979-), male, PhD, associate professor. E-mail: yushouwu@ncst.edu.cn

通讯作者: 王连洲, 教授. E-mail: 1.wang@uq.edu.au WANG Lianzhou, professor. E-mail: 1.wang@uq.edu.au 
device has become an attractive challenging technology. The basic idea is that by integration design and engineering the assembly of the photoelectric conversion layer and the energy storage layer into one in-situ energy conversion and storage system could not only offer multiple functions, such as self-powered ability, weak light buffer and portability, but reduce sunlight fluctuation effect on energy output. This review summarizes the research progress in novel in-situ integrative photovoltaic-storage tandem cells, classified by silicon solar cell, sensitized solar cell and perovskite solar cell. Evaluation of methodology, operational principle, construction feature, and performance parameter are also discussed and critically reviewed, and the further development of in-situ integrative photovoltaic-storage tandem cell is also prospected.

Key words: silicon solar cell; sensitized solar cell; perovskite solar cell; energy storage; photovoltaic-storage; in-situ integration; review

太阳能具有清洁、取之不尽用之不竭、不受地 域限制的优点, 是最具开发潜力的可再生能源之一 ${ }^{[1]}$ 。 近年来, 太阳能加热 ${ }^{[2]}$ 、光伏发电 ${ }^{[3-4]}$ 、光催化 ${ }^{[5-6]}$ 等太阳能利用技术不断发展, 其中将太阳光转化为 电能的太阳能电池技术日新月异, 迄今已开发出了 多种类型的太阳能电池, 例如硅基太阳能电池 ( SiSC)、敏化太阳能电池( SSC)、钙钛矿太阳能电池 (PSC) 等。提供稳定持续的电能是对电池的基本要求, 然而太阳能电池夜间不工作, 弱光转换效率低, 因 此集成太阳能电池模块和存储电能模块(如电容器 和锂电池等) 是解决持续供电问题的必要措施。目前 光伏储电集成器件制备工艺主要有光伏储电物理线 路串联 ${ }^{[7-10]}$ 和光伏储电原位集成两种 ${ }^{[11-13]}$, 其中物 理线路串联的光伏储电系统, 即非原位集成系统, 存在功率密度低、能量密度低、总能量转换效率低, 价格昂贵, 体积硕大, 需要外部电路接通等问题 ${ }^{[14-15]}$ 。 将光电转换功能薄膜部件与储电功能薄膜部件原位 逐层制备并组装, 获得光伏储电原位集成电池技术, 具有高效、能量输出稳定、可持续、环保、可穿戴 等优点, 可适应当前生命科学、信息科学、电子工 业等领域对能源电池小型化、功能化和智能化的发 展要求。而目前还未有关于光伏储电原位集成电池 的综述报道。本文详述了以硅基太阳能电池、敏化 太阳能电池、钙钛矿太阳能电池为光电转换层, 超 级电容器和锂电池等为能量存储层的“三明治”结构 光伏储电原位集成电池的最新研究进展, 讨论了性 能评价方法、工作原理、构造特点和性能参数, 并 对光伏储电原位集成电池的发展趋势进行了展望。

\section{1 光伏储电原位集成电池性能评价}

光伏储电原位集成电池由太阳能电池模块和储 能电池模块两部分组成, 如图 1 所示。其综合性能

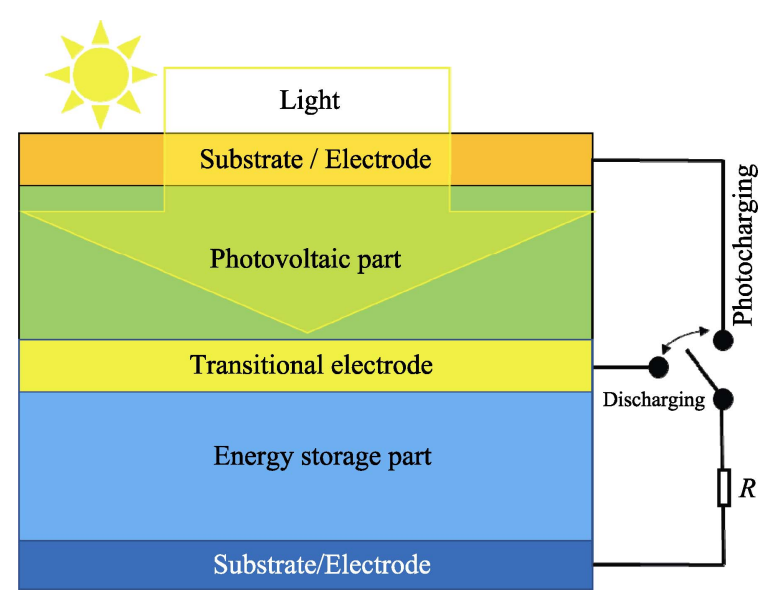

图 1 光伏储电原位集成电池的示意图

Fig. 1 Schematic diagram of an in-situ integrative photovoltaicstorage tandem cell

与太阳能电池的光电转换单元性能和能量储存单元 性能有关 ${ }^{[16-19]}$ 。

太阳能电池模块性能可使用公式 $(1,2)$ 来计算:

$$
\begin{gathered}
\eta_{\text {solar }}=V_{\mathrm{oc}} \cdot J_{\mathrm{sc}} \cdot F F / P_{\text {in }} \\
E_{\text {solar }}=P_{\text {in }} \cdot A_{\text {solar }} \cdot t
\end{gathered}
$$

其中, $\eta_{\text {solar }} V_{\mathrm{oc}}(\mathrm{V}) 、 J_{\mathrm{sc}}\left(\mathrm{mA} / \mathrm{cm}^{2}\right) 、 F F$ 和 $P_{\text {in }}\left(\mathrm{mW} / \mathrm{cm}^{2}\right)$ 分别是太阳能电池转换效率、开路电压、短路电流 密度、填充因子和入射光功率密度(国际标准为 $\left.100 \mathrm{~mW} / \mathrm{cm}^{2}\right) ; E_{\text {solar }}(\mathrm{W})$ 为光电转换功率, $t(\mathrm{~s})$ 为太阳 光照射时间, $A_{\text {solar }}$ 为太阳能电池光吸收面积。

评估储能电池模块的性能, 一般进行不同扫描 速率下的循环伏安测试, 可从曲线中获得储电装置 电容 $C_{\text {storage }}(\mathrm{F})$ 的值, 根据公式(3)可计算出能量储存 性能:

$$
E_{\text {storage }}=0.5 \cdot C_{\text {storage }} \cdot U^{2}
$$

其中, $E_{\text {storage }}(\mathrm{W})$ 为存储的能量, $U(\mathrm{~V})$ 是储能电池模 块的电压。理想状态下, 储能电池模块的电压可以 达到太阳能电池 $V_{\mathrm{oc}}$, 将其带入公式(3)得到理想储 能电池能量 $\left(E_{\max }\right)$ 。故储能电池效率 $\eta_{\text {storage }}$ 可根据等 
式(4)确定：

$$
\eta_{\text {storage }}=E_{\text {storage }} / E_{\max }
$$

综上, 光伏储电原位集成电池的总能量转换效 率 $\eta_{\text {overall }}$ 可以根据等式(5)获得 ${ }^{[11-18]}$ :

$$
\begin{aligned}
& \eta_{\text {overall }}=E_{\text {output }} / E_{\text {input }}=E_{\text {storage }} / E_{\text {solar }}= \\
& 0.5 C_{\text {storage }} \cdot U^{2} /\left(P_{\text {in }} \cdot A_{\text {solar }} \cdot t\right)=\eta_{\text {solar }} \cdot \eta_{\text {storage }}
\end{aligned}
$$

其中, $E_{\text {output }}$ 和 $E_{\text {input }}$ 分别为储能电池模块的电能量 输出和太阳能电池模块的光能量输入。

\section{2 光伏储电原位集成电池}

\section{1 硅基光伏储电原位集成电池}

自 1954 年第一个硅基太阳能电池问世以来 ${ }^{[20]}$, 其制备技术蓬勃发展, 目前在国内外实际应用与工 业生产中占据市场份额 $90 \%$ 左右 ${ }^{[21-24]}$, 原因主要有 两点: 第一, 硅基太阳能电池容易制备大面积器件, 易于推广应用; 第二, 硅基太阳能电池具有较高的 $\eta_{\text {solar }}$ 和相对较低的制备成本。然而硅基太阳能电池 存在对原料纯度要求苛刻、制造工艺复杂、耗电量 大, 并且存储电能装置铅酸蓄电池笨重, 能量密度 低, 溢酸等问题 ${ }^{[25]}$ 。硅基太阳能电池是由硅基体掺 杂 $\mathrm{n}$ 型(磷等)或者 $\mathrm{p}$ 型(硼等)半导体形成 $\mathrm{PN}$ 结, 构 建内建电场，内建电场方向由 $\mathrm{N}$ 型层指向 $\mathrm{P}$ 型层。 当外界光照时, 硅基体吸收太阳光能量, 产生大
量的光生电子和光生空穴。光生电子向 $\mathrm{N}$ 型层移 动, 光生空穴向 $\mathrm{P}$ 型层移动, 形成光生伏特电势, 将两端连成电路则会生成光生电流，也就是直流 电 $^{[26-28]}$ 。

在硅基太阳能电池背光面上, 加接制备超级电 容器或者锂电池储电功能薄膜, 组装成硅基光伏储 电原位集成电池，如图 2(a)所示。孙宝全课题组 ${ }^{[29]}$ 通过金属辅助化学蚀刻精确控制纳米线参数, 并通 过溶液钝化工艺对纳米线表面改性, 制备出 $\eta_{\text {solar }}$ 为 $13.39 \%$ 的高性能聚 $(3,4$-亚乙基二氧噻吩)/聚(苯 乙烯磺酸)包覆的硅基太阳能电池。中间采用双功能 钛膜作为公共电极与超级电容器原位相连, 电容器 单元采用电化学沉积方法制备, 多孔聚乙烯薄膜和 聚乙烯醇-磷酸分别作为电容器的隔膜和电解质, 得到的硅基光伏储电原位集成电池的 $\eta_{\text {overall }}$ 为 10.5\%，如图 2(b)所示。随着微制造技术的进步，激 光刻划工艺显示出工艺简单且成本低的优点，顾敏 课题组 ${ }^{[30]}$ 采用激光刻划的氧化石墨烯薄膜当作储 能电池模块集成在硅基太阳能电池之下，构造一种 光伏储电原位集成电池, 如图 2(c)所示。该光伏储 电原位集成电池的 $\eta_{\text {overall }}$ 为 $9.72 \%$, 其中 $\eta_{\text {solar }} \eta_{\text {storage }}$ 分别为 $15.69 \% 、 62 \%$ 。裴启兵课题组 ${ }^{[19]}$ 将激光刻划 石墨烯超级电容器与硅基光伏器件集成, 并选用金 $(\mathrm{Au})$ 作为连接两个单元的公共电极(图 2(d)), 原位
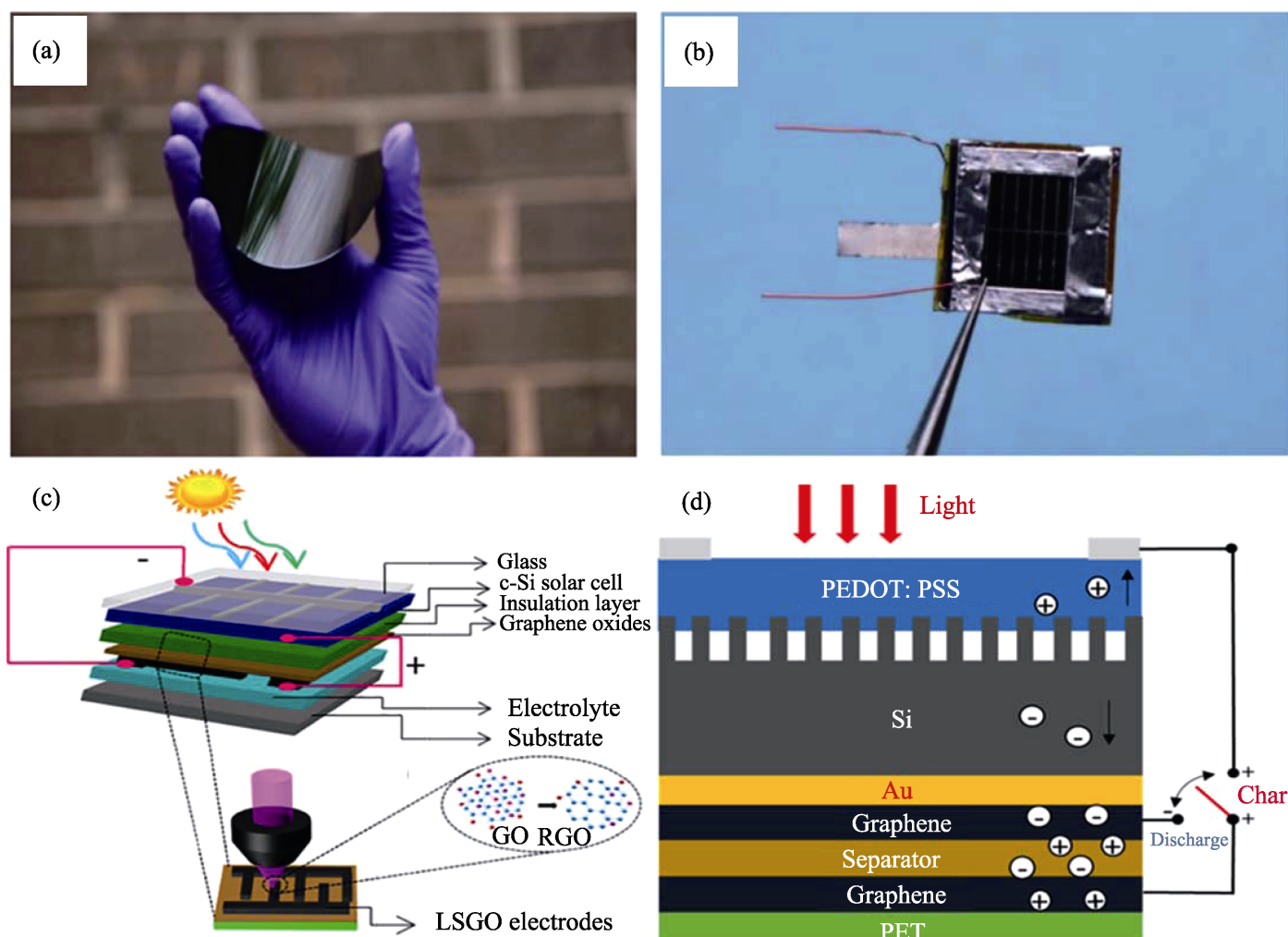

(d)

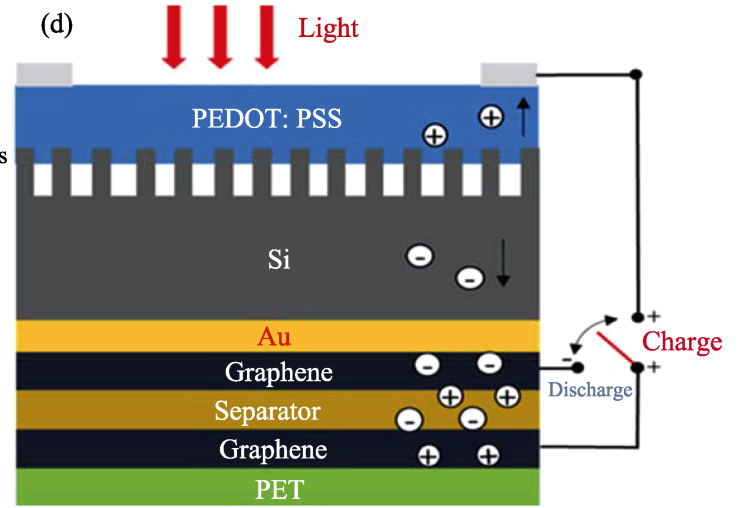

图 2 硅基光伏储电原位集成电池的(a b)照片 ${ }^{[29]}$ 和(c d d)结构示意图 ${ }^{[19,30]}$

Fig. 2 (a-b)Photographs ${ }^{[29]}$ and (c-d) schematic diagrams of in-situ integrated SiSC-storage tandem cells ${ }^{[19,30]}$ 
集成后的光伏储电电池 $\eta_{\text {overall }}$ 为 $2.92 \%$ 。因为 $\mathrm{Au}$ 公 共电极的应用, 获得了优异的充电/放电循环稳定 性。激光刻划工艺制备的石墨烯储能材料具有优异 的功率密度、循环寿命和稳定性能。

除了将硅基太阳能电池与超级电容器结合外, 2017 年 Lee Sang-Young 课题组 ${ }^{[31]}$ 设计了一种将微 型硅基太阳能电池和固态锂离子电池(LIB)原位集 成的可充电便携式电源设备。具有双电极配置的固 态 LIB 通过印刷工艺直接制造在硅基光伏模块上, 使两个不同的能量系统实现无缝原位连接。该集成 组件显示出较好的性能, 其中 $\eta_{\text {solar }}$ 为 $15.8 \%$, 光伏 储电原位集成电池的 $\eta_{\text {overall }}$ 为 $7.61 \%$ 。

上述研究者制备的硅基光伏储电原位集成电池 性能参数见表 1 。硅基光伏储电原位集成电池 $\eta_{\text {solar }}$ 较高且相对稳定, $\eta_{\text {overall }}$ 更多受制于 $\eta_{\text {storage。 }}$ 。

\section{2 敏化光伏储电原位集成电池}

染料敏化太阳能电池，简称 DSSC。自 1991 年 Gräztel 课题组 ${ }^{[32]}$ 制备出第一块光电转化率为 $7.1 \%$ 的二氧化钛纳米多孔薄膜染料敏化太阳能电池以来, 因其可通过卷对卷工艺制造、成本低廉、环保等特 点, 得到了广泛的关注并迅速发展起来, 到目前 DSSC 经美国国家可再生能源实验室(NREL)认证的 光电转换效率最高为 $11.9 \%$ 。典型的 DSSC 主要由 导电基底、半导体纳米多级孔薄膜 $\left(\mathrm{TiO}_{2} 、 \mathrm{ZnO}\right)$ 、染 料敏化剂(N719、C101 等)、含有氧化还原电对的电 解质和对电极几个主要部分组成。目前转换效率较 高的 DSSC 所用的电解质多为液态电解质。太阳光 照时, 染料分子吸收太阳光能量, 从基态激发为激 发态。激发态的染料分子将电子注入到 $\mathrm{TiO}_{2}$ 导带中, 同时染料分子失去电子变为氧化态。注入到 $\mathrm{TiO}_{2}$ 导带中的电子可快速到达膜与导电玻璃的接触面并 且在导电基底富集, 再经外电路流向对电极 ${ }^{[33-35]}$ 。 然而, 液态电解质存在溶剂易挥发泄露、对器件的 封装技术要求高、且长期使用过程中电池效率下降 明显等问题 ${ }^{[36]}$ 。

在敏化太阳能电池光阴极上连续叠层制备储电
薄膜，得到“三明治”结构的原位集成器件，称为敏 化光伏储电原位集成电池, 如图 3(a)所示。2004 年, Miyasaka 等 ${ }^{[12]}$ 报道了一种称之为“光电容器”的组件, 该组件以 DSSC 作为光电转换模块, 超级电容器作 为储能电池模块。在太阳能电池中将 $\mathrm{LiI}$ 与 $\mathrm{TiO}_{2}$ 结 合, 提高了该集成设备的整体性能, 但该类型集成 组件在稳定照明下完全充电后无法提供连续的功率 输出。因此, 该课题组在之后一年通过在工作电极 和对电极之间引入内部双功能电极制备出一种新型 三电极配置的光伏储电原位集成电池，在公共电极 一侧进行光电转换, 在另一侧进行电荷储存, 相比 于双电极系统具有更好的能量储存和输出性能 ${ }^{[37]}$ 。

Segawa 课题组 ${ }^{[38]}$ 在氟掺杂的氧化锡导电层上逐层 制备 N719 染料层、 $\mathrm{TiO}_{2}$ 纳米颗粒层和铂电极, 组 成太阳能电池模块, 其中 $\mathrm{Pt}$ 电极和涂覆有聚吡咯的 电荷存储电极共同连接在同一个梳状电极中, 制备 得到三电极光伏储电原位集成电池, $\eta_{\text {overall }}$ 达到 $3.21 \%$ 。彭慧胜课题组 ${ }^{[39]}$ 制备出一种全固态光伏储 电原位集成电池, 其中储电功能通过将凝胶或固态 电解质夹在对准的多壁碳纳米管(MWCNT)中实现, 再将掺有染料的 $\mathrm{TiO}_{2}$ 敏化光电转换模块制备到其 中一个 MWCNT 电极上, 如图 3(b) 所示。当太阳光 照射时, 来自染料分子的光生成电子被注入到 $\mathrm{TiO}_{2}$ 纳米颗粒的导带中, 然后由外部电路传输到最外层 的 MWCNT 电极, 进行能量的储存。MWCNT 材料 的高比表面积使整个集成电池的 $\eta_{\text {overall }}$ 达到 5.12\%, 其中太阳能电池模块的 $\eta_{\text {solar }}$ 为 $6.1 \%$ 。公共电极材 料直接关系到光伏储电原位集成电池的整体性能, 不少研究者对电极材料的选用进行了探究。江洪睿 课题组 ${ }^{[40]}$ 通过溅射工艺在聚偏二氟乙烯涂层表面 制备了导电 $\mathrm{Au}$ 层, 然后在 $\mathrm{Au}$ 层上电沉积 $\mathrm{Pt}$ 催化剂, 接着在上面制备 $\mathrm{TiO}_{2} / \mathrm{N} 719$ 染料敏化太阳能电池模 块。储能电池模块采用 $\mathrm{ZnO}$ 纳米线阵列复合材料 来提高其储存的电荷密度, 整个光伏储电原位集成 电池的 $\eta_{\text {overall }}$ 为 $3.7 \%$ 。Pint C L 课题组 ${ }^{[4]}$ 通过使用 简单的晶圆级工艺从硅晶片中制备出多功能电极,

表 1 硅基光伏储电原位集成电池的性能参数

Table 1 Performance parameters of in-situ integrative SiSC-storage tandem cells

\begin{tabular}{|c|c|c|c|c|c|}
\hline Solar cell type & Device construction & $\eta_{\text {overall }} * / \%$ & $\eta_{\text {solar }} * / \%$ & $\eta_{\text {storage }} * / \%$ & Ref. \\
\hline \multirow{3}{*}{ SiSC-SPC } & PEDOT:PSS/n-Si/Ti/PE/(PVA/H $\left.\mathrm{PO}_{4}\right) / \mathrm{PE} / \mathrm{Ti}$ & 10.50 & 13.39 & 78.42 & [29] \\
\hline & $\begin{array}{l}\text { Glass/c-Si/Insulation layer/Graphene oxides/ } \\
\text { Electrolyte/Substrate }\end{array}$ & 9.72 & 15.69 & 62.00 & {$[30]$} \\
\hline & PEDOT:PSS/Si/Au/Graphene/Separator/Graphene/PET & 2.92 & 12.37 & 23.61 & [19] \\
\hline SiSC-LIB & $\begin{array}{l}\mathrm{c}-\mathrm{Si} / \mathrm{Al} / \mathrm{SiO}_{2} / \mathrm{Al} / \mathrm{Li}_{4} \mathrm{Ti}_{5} \mathrm{O}_{12} / \text { Soild electrolyte } / \mathrm{LiCoO}_{2} / \\
\mathrm{Al} / \mathrm{Li}_{4} \mathrm{Ti}_{5} \mathrm{O}_{12} / \text { Solid electrolyte} / \mathrm{LiCoO}_{2} / \mathrm{Al}\end{array}$ & 7.61 & 15.80 & 48.16 & [31] \\
\hline
\end{tabular}

\footnotetext{
$* \eta_{\text {solar }}, \eta_{\text {storage }}$ and $\eta_{\text {overall }}$ are the maximum values reported in the literatures
} 

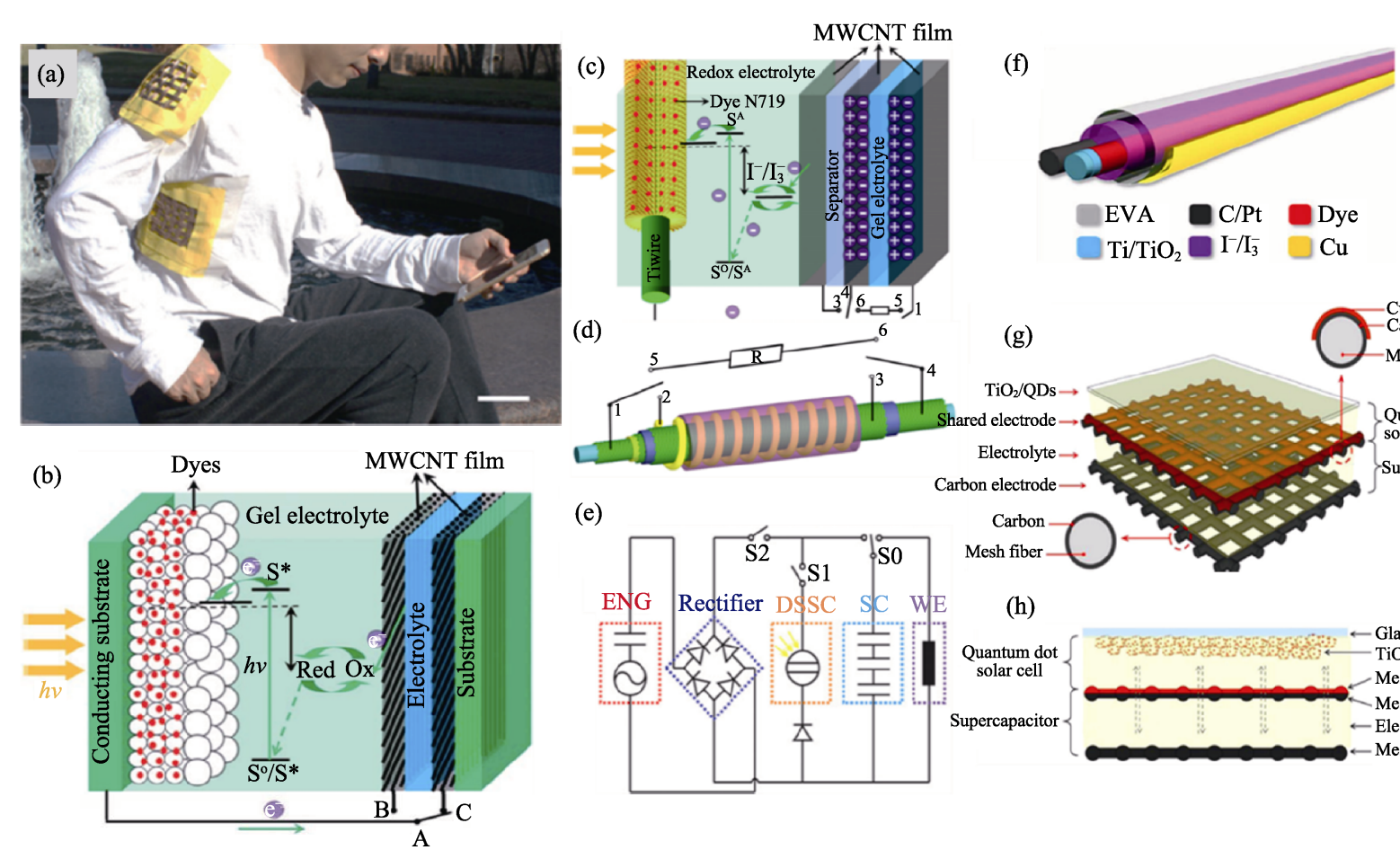

(e)
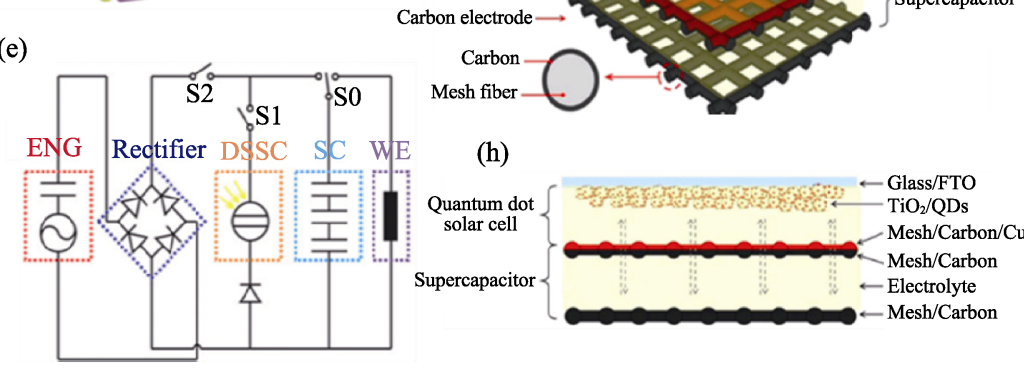

(h)

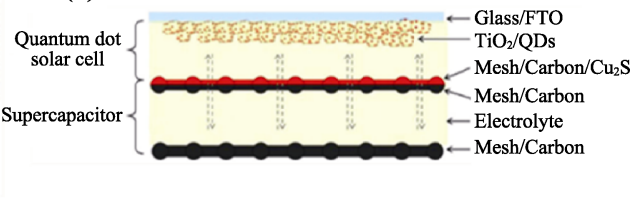

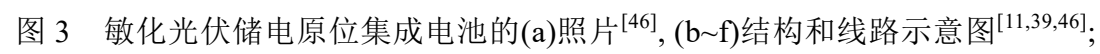

$(\mathrm{g} \sim \mathrm{h})$ 量子点敏化光伏储电原位集成电池的结构示意图 ${ }^{[48]}$

Fig. 3 (a) Photograph ${ }^{[46]}$ and (b-f) schematic diagrams ${ }^{[11,39,46]}$ of in-situ integrated DSSC-storage tandem cells, and (g-h) schematic diagrams of in-situ integrated QDSSC-storage tandem cells ${ }^{[48]}$

该电极取代了常规用于 DSSC 的 Pt 电极, 同时也可 作超级电容器的电极, 该光伏储电原位集成电池的 $\eta_{\text {overall }}$ 为 $2.1 \%$ 。Kulesza 课题组 ${ }^{[42]}$ 将有机染料 D35 改性二氧化钛和聚 3-己基噻酚基共轭聚合物层作为 DSSC 部件, 将氧化钉电池作为储能电池部件, 并 采用银电极作为公共电极, 获得的光伏储电原位集 成电池的 $\eta_{\text {overall }}$ 为 $0.8 \%$ 。

为了满足人们对于电子产品便携化的要求, 国 内外研究者开展了柔性光伏储电原位集成电池的研 发工作。Bella 课题组 ${ }^{[43]}$ 提出了一种柔性可弯曲光伏 储电原位集成电池设备, 该设备由基于 $\mathrm{TiO}_{2}$ 纳米管 的 DSSC 和基于石墨烯的电容器组成。太阳能电池 模块和储能电池模块的公共电极选用钛和不锈钢网 格。采用垂直排列的 $\mathrm{TiO}_{2}$ 纳米管作为 DSSC 光阳极, 石墨烯纳米薄片作为储能电池材料。在两个单元中 间采用甲基丙烯酸酯的聚合物电解质膜(PEM)作为 公共电极和隔离膜, 通过浸泡在两种不同液体电解 质中使之活化。PEM 的使用有效防止了电解液的渗 漏, 确保 DSSC 寿命的同时, 保证了超级电容器有 足够的离子迁移率和储电能力, 该柔性光伏储电原 位集成电池的 $\eta_{\text {overall }}$ 为 $1.46 \%$ 。还有一些研究人员 致力于在纤维上制备光伏储电原位集成电池, 这是 由于纤维具有重量轻、灵活、价格低廉、适合特殊 应用并且能够与布料结合等优点。彭慧胜课题组 ${ }^{[4]}$ 设计了一种光伏储电原位集成线状电池, 同时实现
了良好的光电转换性能和储电性能。他们采用二氧 化钛纳米管对 $\mathrm{Ti}$ 线表面进行改性, 之后去除 $\mathrm{Ti}$ 线中 间和两端的改性部分, 使改性的 $\mathrm{Ti}$ 线分成两部分。 选择改性 $\mathrm{Ti}$ 线的一部分涂覆光活性染料, 另一部分 涂覆电解质, 最后将碳纳米管 $(\mathrm{CNT})$ 与其绞合得到 纤维状集成电池, 该光伏储电原位集成电池 $\eta_{\text {overall }}$ 为 $1.5 \%$, 其 $\eta_{\text {solar }}$ 为 $2.2 \%$ 。该课题组 ${ }^{[45]}$ 优化工艺, 采 用表面上具有垂直排列的二氧化钛纳米管的 $\mathrm{Ti}$ 线 和水平排列的 CNT 作为集成器件中的两个电极, 为 电荷的传输提供了有效的途径, $\eta_{\text {solar }}$ 可提高到 $2.73 \%, \eta_{\text {storage }}$ 为 $75.7 \%$ 。该课题组 ${ }^{[11]}$ 进一步研究采 用化学沉积工艺合成连续、对齐的 CNT 薄膜作为内 部电极缠绕在弹性橡胶纤维上, 接着在其上涂覆聚 乙烯醇-磷酸凝胶, 然后再次包覆相同的 CNT 薄膜, 得到储能电池模块。随即在该模块上叠层制备太阳 能电池模块, $\eta_{\text {overall }}$ 达到 $1.83 \%$, 如图 3(c, d) 所示。邹 德春课题组 ${ }^{[18]}$ 使用聚苯胺涂覆的不锈钢丝作为公 共电极, 将 DSSC 和超级电容器原位结合, 得到重 量轻、灵活和价格低廉的纤维状光伏储电原位集成 电池, $\eta_{\text {overall }} 、 \eta_{\text {solar }}$ 和 $\eta_{\text {storage }}$ 分别为 $2.12 \% 、 4.56 \%$ 和 $46 \%$ 。王中林课题组 ${ }^{[46]}$ 提出了混合自充电动力纺织 系统的概念, 通过使用纤维状染料敏化太阳能电池 (用于太阳能)和纤维状摩擦电纳米发电机(用于随机 体运动能量), 将收集的两种能量较容易地转换成 电能, 然后进一步转换为化学能存储在纤维状储能 
电池器件中, 如图 3(e, f) 所示。

量子点敏化太阳能电池(QDSSC) 是在 DSSC 的基础上发展而来的, 它采用无机半导体量子点 作为敏化剂, 克服了传统有机染料敏化剂吸光范 围较窄的缺点, 并且电池的制备成本更低。目前, 经 NREL 认证, 王连洲课题组 ${ }^{[47]}$ 制备的全固态量 子点太阳能电池的 $\eta_{\text {solar }}$ 为最高记录。俞大鹏课题 组 ${ }^{[48]}$ 使用双面网状电极作为公共电极将 $\mathrm{CdS} / \mathrm{CdSe}$ 量子点敏化太阳能电池与超级电容器 原位集成, 得到一种网状光伏储电原位集成电池, 如图 3(g,h) 所示。

除了上述将敏化太阳能电池与超级电容器原位 集成外, 还可将其与锂离子电池(LIB)、氧化还原液 流电池(RFB) 原位集成。王中林课题组 ${ }^{[49]}$ 提出在具 有双面 $\mathrm{TiO}_{2}$ 纳米管阵列 $\left(\mathrm{TiO}_{2} \mathrm{NT}\right)$ 的钛箔上原位制 备 DSSC 和 LIB, 上部是使用 $\mathrm{TiO}_{2} \mathrm{NT}$ 作为电子收 集器制造的 DSSC, 下部是基于 $\mathrm{TiO}_{2} \mathrm{NT}$ 的 LIB, 用 于存储 DSSC 产生的电能。当太阳光照射时, 产生 的电子从染料分子注入到 $\mathrm{TiO}_{2} \mathrm{NT}$ 的导带中, 并沿 着 $\mathrm{Ti}$ 䇴传输到 LIB 的阳极, 而产生的空穴在 Pt 电极 处积聚, 此时 LIB 部分处于充电状态。来自 DSSC 的 电子与锂离子在阳极发生化学过程为 $\mathrm{TiO}_{2}+x \mathrm{Li}^{+}+$ $x \mathrm{e}^{-} \rightarrow \mathrm{Li}_{x} \mathrm{TiO}_{2}$, 阴极 $\mathrm{LiCoO}_{2} \rightarrow \mathrm{Li}_{1-x} \mathrm{CoO}_{2}+x \mathrm{Li}^{+}+x \mathrm{e}^{-}$, 释放的自由电子将通过外电路流到 DSSC 的对电极,
以与 $\mathrm{Pt}$ 电极中的空穴结合, 完成了电荷生成、分离 和储存的整个过程, 该光伏储电原位集成电池的 $\eta_{\text {overall }}$ 为 $0.82 \%$ 。Ho Kuo-Chuan 课题组 ${ }^{[50]}$ 采用电泳 沉积法将 $\mathrm{TiO}_{2}$ 沉积到基板上并使用染料 N719 作为 光活性层组成太阳能电池模块。并通过公共 $\mathrm{Pt}$ 电极 来连接厚度约为 $0.5 \mathrm{~mm}$ 的聚 $(3,4$-乙烯二氧噻吩)薄 膜锂电池。该课题组在同一年, 将 N3 染料(双)(异硫 氭基)钌(II)-双-2,2-联吡啶-4,4-二羧酸)敏化太阳能 电池与聚 $(3,3-$ 二乙基 $-3,4-$ 二氢 $-2 \mathrm{H}$ - 噻吩并 $[3,4-B][1,4]$ 二氧杂环庚烯) 导电聚合物薄膜 (作为存 储电能模块) 原位集成了光伏储电电池 ${ }^{[51]}$ 。李东栋课 题组 ${ }^{[52]}$ 设计了一种新型光伏储电原位集成电池, 由 DSSC 与基于一维氧化钛纳米管阵列构建的锂电池 组成, 储能电池单元制备过程中采用选择性等离子 体辅助氢化处理, 通过该工艺处理的集成电池 $\eta_{\text {overall }}$ 为 $1.64 \%$ 。高学平课题组 ${ }^{[53]}$ 采用 $\mathrm{I}_{3}{ }^{-} / \mathrm{I}^{-}$和 $\left[\mathrm{Fe}\left(\mathrm{C}_{10} \mathrm{H}_{15}\right)_{2}\right]^{+} / \mathrm{Fe}\left(\mathrm{C}_{10} \mathrm{H}_{15}\right)_{2}$ 氧化还原电解液作为两个 循环回路, 原位集成 DSSC/RFB 电池, 实现了光一化 学-电能的转换和存储。该课题组 ${ }^{[54]}$ 进一步采用喹 喔啉水溶液作为 RFB 阳极电解液, 得到 DSSC 与 $\mathrm{RFB}$ 光伏储电原位集成电池, $\eta_{\text {overall }}$ 为 $1.2 \%$ 。

上述研究者制备的敏化光伏储电原位集成电池 性能参数见表 2 。该类型集成电池受制于相对较低 的 $\eta_{\text {solar }}$, 导致其 $\eta_{\text {overall }}$ 也普遍偏低。

表 2 敏化光伏储电原位集成电池的性能参数

Table 2 Performance comparison of in-situ integrative SSC-storage tandem cells

\begin{tabular}{|c|c|c|c|c|c|}
\hline Solar cell type & Device construction & $\eta_{\text {overall }} * / \%$ & $\eta_{\text {solar }} * / \%$ & $\eta_{\text {storage }} * / \%$ & Ref. \\
\hline \multirow{12}{*}{ DSSC-SPC } & FTO/TiO ${ }_{2} @$ dye $/ \mathrm{LiI} /$ Carbon layer/Porous separator/C/Pt & - & - & 59.00 & {$[12]$} \\
\hline & $\mathrm{FTO} / \mathrm{TiO}_{2} @ \mathrm{~N} 719 / \mathrm{I}^{-} / \mathrm{I}_{3}{ }^{-} / \mathrm{Pt} /$ Carbon/Separator/Electrolyte/C/Pt & - & - & 42.00 & [37] \\
\hline & $\mathrm{TCO} / \mathrm{TiO}_{2} @ \mathrm{~N} 719 / \mathrm{I}^{-} / \mathrm{I}_{3}^{-}$gel/MWCNT $/ \mathrm{PVA}-\mathrm{H}_{3} \mathrm{PO}_{4} / \mathrm{MWCNT}$ & 5.12 & 6.10 & 84.00 & [39] \\
\hline & FTO/TiO ${ }_{2} @ \mathrm{~N} 719 / \mathrm{I}^{-} / \mathrm{I}_{3}^{-} / \mathrm{Zn} \mathrm{NWs@PVDF@Au@Pt/FTO}$ & 3.70 & - & - & {$[40]$} \\
\hline & Glass/FTO/TiO ${ }_{2} @$ dye $/ \mathrm{I}^{-} / \mathrm{I}_{3}^{-} / \mathrm{Si} /$ Ionic polymer/Si wafer & 2.10 & 2.63 & 80.00 & [41] \\
\hline & $\begin{array}{l}\mathrm{FTO} / \mathrm{TiO}_{2}-\mathrm{D} 365 \text { dye } / \mathrm{P} 3 \mathrm{HT} / \mathrm{Ag} / \mathrm{RuO}_{x}(\mathrm{OH})_{y} / \text { Nafion membrane/ } \\
\mathrm{RuO}_{x}(\mathrm{OH})_{y} / \mathrm{FTO}\end{array}$ & 0.80 & 0.91 & 88.00 & {$[42]$} \\
\hline & $\mathrm{Ti} / \mathrm{TiO}_{2} @ \mathrm{~N} 719 / \mathrm{I}^{-} / \mathrm{I}_{3}^{-} / \mathrm{Pt} / \mathrm{Parafilm} / \mathrm{C} / \mathrm{PVDF} / \mathrm{SS}$ & 1.46 & 2.03 & 71.56 & [43] \\
\hline & CNT fiber@CNTs/Ti wire/TiO ${ }_{2} @ N 719 / \mathrm{I}^{-} / \mathrm{I}_{3}{ }^{-} / \mathrm{CNT}$ fiber & 1.50 & 6.10 & 84.00 & [44] \\
\hline & Tiwire/TiO ${ }_{2} @ \mathrm{~N} 719 /$ Eutectic melts/CNTs-Ti wire/ $\mathrm{TiO}_{2} / \mathrm{PVA}-\mathrm{H}_{3} \mathrm{PO}_{4} / \mathrm{CNT}$ & 2.07 & 2.73 & 75.70 & [45] \\
\hline & Ti/TiO ${ }_{2} @ N 719 / \mathrm{I}^{-} / \mathrm{I}_{3}^{-} / \mathrm{MWCNT} /$ Separator/MWCNT/PVA- ${ }_{3} \mathrm{PO}_{4} / \mathrm{MWCNT}$ & 1.83 & 6.47 & 28.30 & {$[11]$} \\
\hline & $\begin{array}{l}\text { Ti Fiber@ } \mathrm{TiO}_{2} @ \text { dye } / \mathrm{I}^{-} / \mathrm{I}_{3}^{-} / \text {Stainless steel(ss)@PANi-SS@Space } \\
\text { wire } / \mathrm{H}_{2} \mathrm{SO}_{4} / \mathrm{ss} @ \mathrm{PANi}\end{array}$ & 2.12 & 4.56 & 46.00 & {$[18]$} \\
\hline & $\begin{array}{l}\mathrm{Ti} / \mathrm{TiO}_{2} @ \mathrm{~N} 719 / \mathrm{I}^{-} / \mathrm{I}_{3}{ }^{-} / \text {Carbon fiber(CF)/EVA/Cu-CF@ } \\
\mathrm{RuO}_{2} \cdot x \mathrm{H}_{2} \mathrm{O} / \mathrm{H}_{3} \mathrm{PO}_{4} / \mathrm{PVA} / \mathrm{CF} @ \mathrm{RuO}_{2} \cdot x \mathrm{H}_{2} \mathrm{O} / \mathrm{EVA} / \mathrm{Cu} / \mathrm{PDMS}\end{array}$ & - & 5.64 & - & {$[46]$} \\
\hline QDSSC-SPC & Glass/FTO/TiO ${ }_{2} @ \mathrm{CdS} / \mathrm{CdSe} / \mathrm{S}^{2-} / \mathrm{S} / \mathrm{Cfiber} @ \mathrm{Cu}_{2} \mathrm{~S} / \mathrm{C} /$ Electrolyte/C & & 1.8 & & [48] \\
\hline \multirow{5}{*}{ DSSC-LIB } & Pt/Electrolyte/TNTs@N719/Ti/TNTs/Membrane/LiCoO $2 / \mathrm{Al}$ & 0.82 & - & - & [49] \\
\hline & $\mathrm{PEN} / \mathrm{ITO} / \mathrm{TiO}_{2} @ \mathrm{~N} 719 / \mathrm{I}^{-} / \mathrm{I}_{3}{ }^{-} / \mathrm{Pt} / \mathrm{PEDOT} / \mathrm{LiClO}_{4} / \mathrm{PEDOT} / \mathrm{Pt}$ & - & 4.37 & - & {$[50]$} \\
\hline & $\mathrm{FTO} / \mathrm{TiO}_{2} @ \mathrm{~N} 3 / \mathrm{I}^{-} / \mathrm{I}_{3}^{-} / \mathrm{Pt} / \mathrm{PProDOT} \mathrm{Et}_{2} / \mathrm{LiClO}_{4} / \mathrm{PProDOT} \mathrm{Et}_{2} / \mathrm{Pt}$ & 0.60 & 0.75 & 80.00 & [51] \\
\hline & $\begin{array}{l}\mathrm{FTO} / \mathrm{Pt} / \mathrm{I}^{-} / \mathrm{I}_{3}{ }^{-} / \mathrm{TiO}_{2} \text { nanotube }(\mathrm{ATO}) @ \mathrm{~N} 749 / \mathrm{Ti} / \\
\mathrm{ATO} / \mathrm{Separator} / \mathrm{Li}_{2} \mathrm{SO}_{4} / \mathrm{ATO} / \mathrm{Ti} / \mathrm{FTO}\end{array}$ & 1.64 & 3.18 & 51.60 & {$[52]$} \\
\hline & FTO/TiO ${ }_{2} @$ bis-EDOT dye/PEDOT/C/LiClO $4 /$ electrolyte/ppy/FTO & 0.10 & - & - & {$[53]$} \\
\hline
\end{tabular}

$* \eta_{\text {solar }}, \eta_{\text {storage }}$ and $\eta_{\text {overall }}$ are the maximum values reported in literatures. 


\section{3 钙钛矿光伏储电原位集成电池}

钙钛矿太阳能电池(PSC), 其钙钛矿材料具有特 征化学式 $\mathrm{ABX}_{3}, 20$ 世纪 90 年代 Mitzi 及其同事 ${ }^{[55-56]}$ 首次将其应用于发光二极管和晶体管, 其中的 $\mathrm{A}$ 为 有机阳离子 $\left(\mathrm{CH}_{3} \mathrm{NH}_{3}^{+}\left(\mathrm{MA}^{+}\right) 、 \mathrm{NH}_{2} \mathrm{CH}=\mathrm{NH}_{2}^{+}\left(\mathrm{FA}^{+}\right), \mathrm{B}\right.$ 为金属阳离子 $\left(\mathrm{Sn}^{2+} 、 \mathrm{~Pb}^{2+}\right), \mathrm{X}$ 为卤化物阴离子 $\left(\mathrm{Cl}^{-}\right.$、 $\left.\mathrm{I}^{-} 、 \mathrm{Br}^{-}\right) 。 2009$ 年, Miyasaka 课题组 ${ }^{[57]}$ 报道了将钙钛 矿材料作为敏化剂组装到太阳能电池中, 得到太阳 能电池转换效率为 $3.81 \%$ 。随后的研究揭示了钙钛 矿材料的更多优势，包括带隙可调、吸收系数高、 载流子迁移率高等 ${ }^{[58]}$ 。由于液态电解质存在漏液等 问题, 钙钛矿太阳能电池的研究方向转向固态电 池。该电池分为正式(n-i-p)和反式(p-i-n)两种结构, 其中正式 $\mathrm{n}-\mathrm{i}-\mathrm{p}$ 结构为导电层 $(\mathrm{p}$ 型层)/电子传输层 ( $\mathrm{n}$ 型层)/钙钛矿吸光层/空穴传输层/电极, 反式 $\mathrm{p}-\mathrm{i}-\mathrm{n}$ 结构为导电层/空穴传输层/钙钛矿吸光层/电子传输 层/电极。光照时钻钛矿层吸收光能并且激发出大量 的电子-空穴对, 电子、空穴分别由 $\mathrm{n}$ 型层和 $\mathrm{p}$ 型层 收集并传输给电极, 形成电路 ${ }^{[59-69]}$ 。到目前为止，钙 钛矿太阳能电池经 NREL 认证的 $\eta_{\text {solar }}$ 最高达到 $25.2 \%{ }^{[57-70]}$ 。

在钙钛矿太阳能电池基础上原位制备电容器 或锂电池薄膜, 得到钙钛矿光伏储电原位集成电 池, 如图 4(a)所示。在 2015 年, 王鸣魁课题组 ${ }^{[71]}$ 将钙钛矿太阳能电池和聚吡咯超级电容器原位集 成光伏储电电池, 该钙钛矿太阳能电池模块结构 为 $\mathrm{FTO} / \mathrm{TiO}_{2} / \mathrm{CH}_{3} \mathrm{NH}_{3} \mathrm{PbI}_{3} /$ Spiro-OMeTAD $/ \mathrm{Au}$, 获 得钙钛矿太阳能电池的 $\eta_{\text {solar }}$ 为 $13.6 \%$ 。在标准太阳
光 $\left(100 \mathrm{~mW} / \mathrm{cm}^{2}\right)$ 照射下器件具有 $1.45 \mathrm{~V}$ 的高输出电 压, $\eta_{\text {overall }}$ 达到了 $10 \%$ 。金钟课题组 ${ }^{[72]}$ 利用碳电极原 位集成光电转换模块与能量存储模块, 该光伏储电 原位集成电池结构为 $\mathrm{FTO} /$ 致密 $\mathrm{TiO}_{2}\left(\mathrm{c}-\mathrm{TiO}_{2}\right) /$ 个孔 $\mathrm{TiO}_{2}\left(\mathrm{~m}-\mathrm{TiO}_{2}\right) / \mathrm{CH}_{3} \mathrm{NH}_{3} \mathrm{PbI}_{3} /$ 碳电极/凝胶电解质/碳 电极。在太阳光照射过程中, $\mathrm{CH}_{3} \mathrm{NH}_{3} \mathrm{PbI}_{3}$ 层吸收光 并产生电子-空穴对, 之后电子-空穴对快速分离, 电子被转移到超级电容器单元的外电极, 空穴存储 在光伏和超级电容器共用碳电极上。以这种方式, 光伏单元上的连续光照射可以有效地实现光电荷的 产生和转移, 给超级电容器单元提供快速充电。该 装置结构简单、紧凑, $\eta_{\text {overall }}$ 达到 $7.1 \%$ 。廖广兰课题 组 ${ }^{[13]}$ 采用刮涂法制备碳电极作为公共电极, 在公共 碳电极上制备钙钛矿太阳能电池来进行光电转换, 在另一面制备非对称 $\mathrm{MnO}_{2}$ 电容器进行能量储存, 如图 4(b)所示, 该光伏储电原位集成电池的 $\eta_{\text {overall }}$ 为 $5.26 \%$ 。除了采用常见的碳电极作为公共电极, Lee Kwanghee 课题组 ${ }^{[73]}$ 制备出基于聚乙烯醇-磷酸 的固态超级电容器, 并在其上制备钙钦矿太阳能电 池模块。由于采用含银环氧树脂电极将钙钛矿太阳 能电池与超级电容器原位互连, 光伏储电原位集成 电池表现出高的 $\eta_{\text {storage }}$ 和 $\eta_{\text {overall }}$, 分别为 $80.31 \%$ 和 $10.97 \%$, 如图 4(c)所示。考虑到钙铁矿材料遇水会 降解, 刘长虹课题组 ${ }^{[74]}$ 通过在钙钛矿太阳能电池和 电容器之间制备超级碳纳米管层(SACNT)来提高集 成电池的稳定性, SACNT 能减少电容器中凝胶电解 质对钙钛矿材料的降解。钙钛矿光伏原位集成电池 在可穿戴技术领域也取得了可喜的进展，Thomas

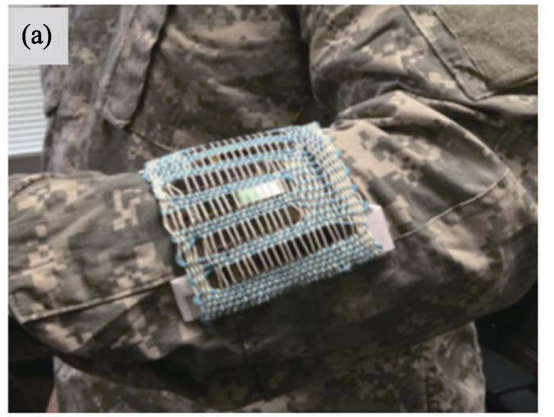

(c) <Charging $>$

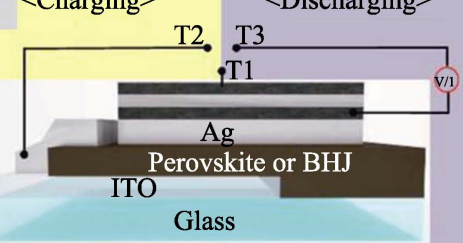

$<$ Self-charging power pack $>$ (b)

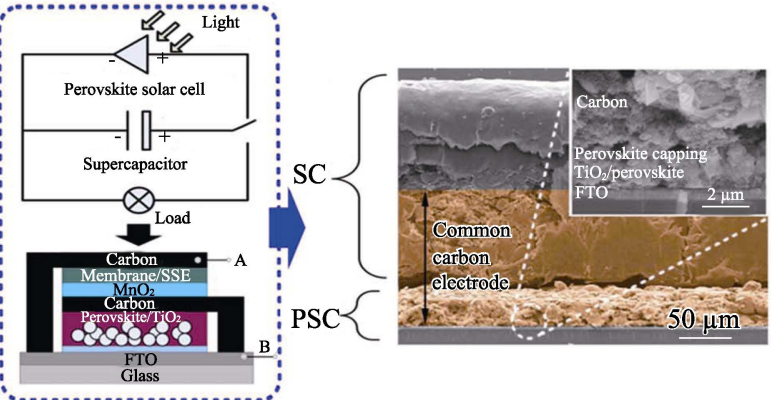

(d)

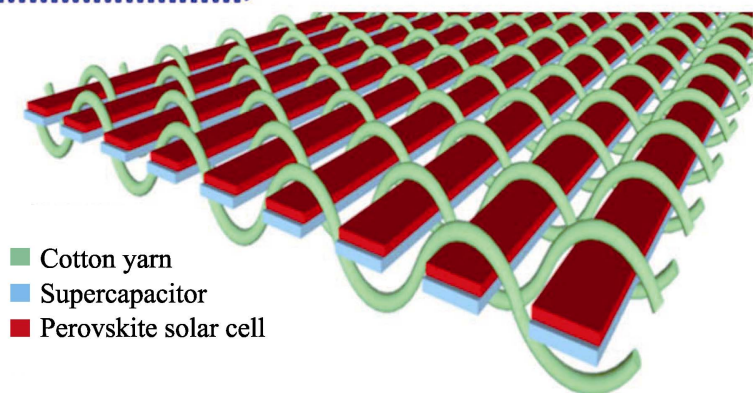

图 4 钲钛矿光伏储电原位集成电池的 $(\mathrm{a})$ 照片 ${ }^{[75]},(\mathrm{b} \sim \mathrm{d})$ 结构和线路示意图 ${ }^{[13,73,75]}$

Fig. 4 (a) Photograph ${ }^{[75]}$ and (b-d) schematic diagrams of in-situ integrated PSC-storage tandem cells ${ }^{[13,73,75]}$ 
表 3 PSC-SPC 型钙钛矿光伏储电原位集成电池的性能参数

Table 3 Performance comparison of in-situ integrative PSC-storage tandem cells

\begin{tabular}{|c|c|c|c|c|}
\hline Device construction & $\eta_{\text {overall }} * / \%$ & $\eta_{\text {solar }} * / \%$ & $\eta_{\text {storage }} * / \%$ & Ref. \\
\hline $\mathrm{FTO} / \mathrm{c}-\mathrm{TiO}_{2} / \mathrm{m}-\mathrm{TiO}_{2} / \mathrm{CH}_{3} \mathrm{NH}_{3} \mathrm{PbI}_{3} /$ Carbon/Gel electrolyte/Carbon & 7.10 & 9.60 & 73.96 & {$[72]$} \\
\hline $\mathrm{FTO} / \mathrm{TiO}_{2} /$ Perovskite/Carbon $/ \mathrm{MnO}_{2} /$ Membrane SSE$/$ Carbon & 5.26 & 7.79 & 67.50 & [13] \\
\hline ITO/pss/PTAA/Perovskite/PCBM/PEI/Ag/GRO/PVA/Separator/PVA/GRO & 10.97 & 13.66 & 80.31 & [73] \\
\hline $\mathrm{FTO} / \mathrm{TiO}_{2} / \mathrm{CH}_{3} \mathrm{NH}_{3} \mathrm{PbI}_{3} / \mathrm{MWCNT} / \mathrm{PMMA} / \mathrm{PVA} / \mathrm{PANI} @ \mathrm{acSACNT} / \mathrm{PMMA} / \mathrm{SACNT}$ & 1.92 & 2.71 & 70.90 & [74] \\
\hline $\begin{array}{l}\mathrm{PET} / \mathrm{ITO} / \mathrm{PEDOT}: \mathrm{PSS} / \mathrm{CH}_{3} \mathrm{NH}_{3} \mathrm{PbI}_{3} / \mathrm{PCBM} / \mathrm{CuOHNT} / \mathrm{AgNW} / \mathrm{AuPd} / \mathrm{MnO}_{2} / \mathrm{KOH} / \mathrm{PV} \\
\mathrm{A} / \mathrm{MnO}_{2} / \mathrm{AuPd} / \mathrm{AgNW} / \mathrm{CuOHNT}\end{array}$ & 6.97 & 10.41 & 67.00 & {$[75]$} \\
\hline
\end{tabular}

$* \eta_{\text {solar }}, \eta_{\text {storage }}$ and $\eta_{\text {overall }}$ are the maximum values reported in the literatures

Jayan 课题组 ${ }^{[75]}$ 报道了一种能量收集和存储色带, 其通过铜 $(\mathrm{Cu})$ 色带作为公共电极与 PSC 集成得到光 伏储电原位集成电池, 其中 $\mathrm{Cu}$ 色带不仅用作太阳 能电池的电子收集电极, 还用作生长超级电容器的 氢氧化铜纳米管 $(\mathrm{CuOHNT})$ 的基板。通过将含有氢 氧化钾凝胶电解质的聚乙烯醇粘合到公共 $\mathrm{Cu}$ 电极 的 CuOHNT 生长侧, 开发储能电池模块。利用 $\mathrm{Cu}$ 公共电极, 柔性薄膜 PSC 产生的电荷直接传输并存 储在超级电容器中。在铜带上开发柔性光伏储电原 位集成电池可以为可穿戴设备和其他便携式设备提 供灵活的自给能量系统, 如图 4(d)所示。赵晋津课 题组 ${ }^{[76]}$ 致力于柔性透明耐高温无机云母(Mica)为基 底的钙钛矿太能电池的研究, 目前该型电池的 $\eta_{\text {solar }}$ 达到 $18 \%$ 。同时, 王连洲课题组 ${ }^{[77]}$ 将钙钛矿太阳能 电池的 $\mathrm{Al}$ 电极扩展, 制备了钙钛矿太阳能电池集成 铝离子电池薄膜能量组, $\eta_{\text {overall }}$ 达到 $12.04 \%$ 。上述研 究有望推进便携、高效的柔性钙钛矿光伏储电原位 集成电池的发展。

上述研究者制备的钙钛矿光伏储电原位集成电 池性能参数见表 3 。近年来 PSC 异军突起, 实验室 阶段的光电转化效率快速提高, 但目前钙钛矿太阳 能电池还存在一些需要攻克的难点, 例如稳定性、 界面问题和成本等。

\section{3 总结与展望}

本文概述了各类太阳能电池模块和储能电池模 块原位集成的光伏储电电池的发展情况, 重点介绍 了 SiSC、SSC 和 PSC 作为光电转换部件, 与电容器 或锂电池等储能电池部件集成的光伏储电原位集成 固态或柔性电池。光伏储电原位集成电池具有优异 的性能, 如稳定性、灵活性和智能性等。目前硅基 光伏储电原位集成电池的 $\eta_{\text {overall }}$ 已经达到 $10.5 \%$, 敏化光伏储电原位集成电池的 $\eta_{\text {overall }}$ 达到 $5.12 \%$, 相比之下, 钻铁矿光伏储电原位集成电池的 $\eta_{\text {overall }}$
已达到 $10.97 \%$ ，且效率仍有提高空间，说明钙钛矿 太阳能电池与储能电池部件原位集成具有良好的发 展前景。光伏储电原位集成电池是由太阳能电池模 块和储能电池模块集成的, 两个模块的性能直接决 定了 $\eta_{\text {overall }}$ 的高低, 两个模块的原位结构设计也关 系到整体性能。未来光伏储电原位集成电池的研发 应向商业化发展, 以满足传感器网络、可穿戴设备 和电子产品等方面的实际应用。

\section{参考文献:}

[1] CELIK I, PHILLIPS A B, SONG Z N, et al. Environmental analysis of perovskites and other relevant solar cell technologies in a tandem configuration. Energy \& Environmental Science, 2017, 10(9): 1874-1884.

[2] SHUKLA R, SUMATHY K, ERICKSON P, et al. Recent advances in the solar water heating systems: a review. Renewable and Sustainable Energy Reviews, 2013, 19: 173-190.

[3] HEDLEY G J, RUSECKAS A, SAMUEL I D W. Light harvesting for organic photovoltaics. Chemical Reviews, 2016, 117(2): 796-837.

[4] IONESCU C, BARACU T, VLAD G E, et al. The historical evolution of the energy efficient buildings. Renewable and Sustainable Energy Reviews, 2015, 49: 243-253.

[5] SHARMA S, JAIN K K, SHARMA A. Solar cells: in research and applications - a review. Materials Sciences and Applications, 2015 , 6(12): 1145 .

[6] RAN J R, ZHANG J, YU J G, et al. Earth-abundant cocatalysts for semiconductor-based photocatalytic water splitting. Chemical Society Reviews, 2014, 43(22): 7787-7812.

[7] YUAN Y L, LU Y D, JIA B E, et al. Integrated system of solar cells with hierarchical $\mathrm{NiCo}_{2} \mathrm{O}_{4}$ battery-supercapacitor hybrid devices for self-driving light-emitting diodes. Nano-Micro Letters, 2019, 11(1): 42.

[8] YUAN Y L, WU Y H, ZHANG T, et al. Integration of solar cells with hierarchical $\operatorname{CoS}_{x}$ nanonets hybrid supercapacitors for self-powered photodetection systems. Journal of Power Sources, 2018, 404: 118-125.

[9] SELVAM S, BALAMURALITHARAN B, KARTHICK S N, et al. Novel high-temperature supercapacitor combined dye sensitized solar cell from a sulfated $\beta$-cyclodextrin/PVP/ $/ \mathrm{MnCO}_{3}$ composite. Journal of Materials Chemistry A, 2015, 3(19): 10225-10232.

[10] HASSANALIERAGH M, SOYATA T, NADEAU A, et al. UR-SolarCap: an open source intelligent auto-wakeup solar energy harvesting system for supercapacitor-based energy buffering. IEEE Access, 2016, 4: 542-557. 
[11] YANG Z B, DENG J, SUN H, et al. Self-powered energy fiber: energy conversion in the sheath and storage in the core. Advanced Materials, 2014, 26(41): 7038-7042.

[12] MIYASAKA T, MURAKAMI T N. The photocapacitor: an efficient self-charging capacitor for direct storage of solar energy. Applied Physics Letters, 2004, 85(17): 3932-3934.

[13] LIU Z Y, ZHONG Y, SUN B, et al. Novel integration of perovskite solar cell and supercapacitor based on carbon electrode for hybridizing energy conversion and storage. ACS Applied Materials \& Interfaces, 2017, 9(27): 22361-22368.

[14] GURUNG A, QIAO Q Q. Solar charging batteries: advances, challenges, and opportunities. Joule, 2018, 2(7): 1217-1230.

[15] SCHMIDT D, HAGER M D, SCHUBERT U S. Photo-rechargeable electric energy storage systems. Advanced Energy Materials, 2016, 6(1): 1500369 .

[16] LECHENE B P, CLERC R, ARIAS A C. Theoretical analysis and characterization of the energy conversion and storage efficiency of photo-supercapacitors. Solar Energy Materials and Solar Cells, 2017, 172: 202-212.

[17] LIU R Y, LIU Y Q, ZOU H Y, et al. Integrated solar capacitors for energy conversion and storage. Nano Research, 2017, 10(5): $1545-1559$.

[18] FU Y P, WU H W, YE S Y, et al. Integrated power fiber for energy conversion and storage. Energy \& Environmental Science, 2013, 6(3): $805-812$.

[19] LIU H H, LI M P, KANER R B, et al. Monolithically integrated self-charging power pack consisting of a silicon nanowire array/ conductive polymer hybrid solar cell and a laser-scribed graphene supercapacitor. ACS Applied Materials \& Interfaces, 2018, 10(18): 15609-15615.

[20] CHAPIN D M, FULLER C S, PEARSON G L. A new silicon p-n junction photocell for converting solar radiation into electrical power. Journal of Applied Physics, 1954, 25(5): 676-677.

[21] ALI H, KOUL S, GREGORY G, et al. In situ transmission electron microscopy study of molybdenum oxide contacts for silicon solar cells. Physica Status Solidi (a), 2019, 216(7): 1800998.

[22] CHAN C E, WENHAM S R, HALLAM B J, et al. Monolithically integrated solar cell system. U.S, 10/211,354. 2019-2-19.

[23] NOGAY G, SAHLI F, WERNER J, et al. 25.1\%-efficient monolithic perovskite/silicon tandem solar cell based on a p-type monocrystalline textured silicon wafer and high-temperature passivating contacts. ACS Energy Letters, 2019, 4(4): 844-845.

[24] ZHAO X W, WU H S, YANG L S, et al. High efficiency CNT-Si heterojunction solar cells by dry gas doping. Carbon, 2019, 147: 164-171.

[25] WU X W, LI J Y, TAN Y. Technology of preparing diamond wire cut multicrystalline silicon wafer texture surface. Journal of Inorganic Materials, 2017, 32(9): 985-990.

[26] LIU X J, JIA L J, FAN G P, et al. Au nanoparticle enhanced thin-film silicon solar cells. Solar Energy Materials and Solar Cells, 2016, 147: 225-234.

[27] REN X D, ZI W, MA Q, et al. Topology and texture controlled $\mathrm{ZnO}$ thin film electrodeposition for superior solar cell efficiency. Solar Energy Materials and Solar Cells, 2015, 134: 54-59.

[28] LIU X J, ZI W, LIU S Z. p-Layer bandgap engineering for high efficiency thin film silicon solar cells. Materials Science in Semiconductor Processing, 2015, 39: 192-199.

[29] LIU R Y, WANG J, SUN T, et al. Silicon nanowire/polymer hybrid solar cell-supercapacitor: a self-charging power unit with a total efficiency of 10.5\%. Nano Letters, 2017, 17(7): 4240-4247.

[30] THEKKEKARA L V, JIA B H, ZHANG Y, et al. On-chip energy storage integrated with solar cells using a laser scribed graphene oxide film. Applied Physics Letters, 2015, 107(3): 031105.

[31] UM H D, CHOI K H, HWANG I, et al. Monolithically integrated, photo-rechargeable portable power sources based on miniaturized $\mathrm{Si}$ solar cells and printed solid-state lithium-ion batteries. Energy \& Environmental Science, 2017, 10(4): 931-940.

[32] O'REGAN B, GRÄTZEL M. A low-cost, high-efficiency solar cell based on dye-sensitized colloidal $\mathrm{TiO}_{2}$ films. Nature, 1991, 353(6346): 737.

[33] YUN S, FREITAS J N, NOGUEIRA A F, et al. Dye-sensitized solar cells employing polymers. Progress in Polymer Science, 2016, 59: $1-40$.

[34] SU'AIT M S, RAHMAN M Y A, AHMAD A. Review on polymer electrolyte in dye-sensitized solar cells (DSSCs). Solar Energy, 2015, 115: 452-470.

[35] MAHMOOD A. Recent research progress on quasi-solid-state electrolytes for dye-sensitized solar cells. Journal of Energy Chemistry, 2015, 24(6): 686-692.

[36] MENG X D, YIN M, SHU T, et al. Research progress on counter electrodes of quantum dot-sensitized solar cells. Journal of Inorganic Materials, 2018, 33(5): 483-493.

[37] MURAKAMI T N, KAWASHIMA N, MIYASAKA T. A highvoltage dye-sensitized photocapacitor of a three-electrode system. Chemical Communications, 2005(26): 3346-3348.

[38] SAITO Y, OGAWA A, UCHIDA S, et al. Energy-storable dye-sensitized solar cells with interdigitated nafion/polypyrrole-Pt comb-like electrodes. Chemistry Letters, 2010, 39(5): 488-489.

[39] YANG Z B, LI L, LUO Y F, et al. An integrated device for both photoelectric conversion and energy storage based on free-standing and aligned carbon nanotube film. Journal of Materials Chemistry A, 2013, 1(3): 954-958.

[40] ZHANG X, HUANG X Z, LI C S, et al. Dye-sensitized solar cell with energy storage function through $\mathrm{PVDF} / \mathrm{ZnO}$ nanocomposite counter electrode. Advanced Materials, 2013, 25(30): 4093-4096.

[41] COHN A P, ERWIN W R, SHARE K, et al. All silicon electrode photocapacitor for integrated energy storage and conversion. Nano Letters, 2015, 15(4): 2727-2731.

[42] SKUNIK-NUCKOWSKA M, GRZEJSZCZYK K, KULESZ P J, et al. Integration of solid-state dye-sensitized solar cell with metal oxide charge storage material into photoelectrochemical capacitor. Journal of Power Sources, 2013, 234: 91-99.

[43] SCALIA A, BELLA F, LAMBERTI A, et al. A flexible and portable powerpack by solid-state supercapacitor and dye-sensitized solar cell integration. Journal of Power Sources, 2017, 359: 311-321.

[44] CHEN T, QIU L B, YANG Z L, et al. An integrated "energy wire" for both photoelectric conversion and energy storage. Angewandte Chemie International Edition, 2012, 51(48): 11977-11980.

[45] CHEN X L, SUN H, YANG Z B, et al. A novel "energy fiber" by coaxially integrating dye-sensitized solar cell and electrochemical capacitor. Journal of Materials Chemistry A, 2014, 2(6): 1897-1902.

[46] WEN Z, YEH M H, GUO H Y, et al. Self-powered textile for wearable electronics by hybridizing fiber-shaped nanogenerators, solar cells, and supercapacitors. Science Advances, 2016, 2(10): e1600097.

[47] Best Research-Cell Efficiency Chart(NREL). https://www.nrel. gov/pv/cell-efficiency.html.

[48] SHI C L, DONG H, ZHU R, et al. An "all-in-one" mesh-typed integrated energy unit for both photoelectric conversion and energy storage in uniform electrochemical system. Nano Energy, 2015, 13: 670-678.

[49] GUO W X, XUE X Y, WANG S H, et al. An integrated power pack of dye-sensitized solar cell and Li battery based on double-sided $\mathrm{TiO}_{2}$ nanotube arrays. Nano Letters, 2012, 12(5): 2520-2523. 
[50] CHEN H W, HSU C Y, CHEN J G, et al. Plastic dye-sensitized photo-supercapacitor using electrophoretic deposition and compression methods. Journal of Power Sources, 2010, 195(18): 6225-6231.

[51] HSU C Y, CHEN H W, LEE K M, et al. A dye-sensitized photo-supercapacitor based on PProDOT-Et ${ }_{2}$ thick films. Journal of Power Sources, 2010, 195(18): 6232-6238.

[52] XU J, WU H, LU L F, et al. Integrated photo-supercapacitor based on bi-polar $\mathrm{TiO}_{2}$ nanotube arrays with selective one-side plasma-assisted hydrogenation. Advanced Functional Materials, 2014, 24(13): 1840-1846.

[53] LIU P, CAO Y L, LI G R, et al. A solar rechargeable flow battery based on photoregeneration of two soluble redox couples. ChemSusChem, 2013, 6(5): 802-806.

[54] YAN N F, LI G R, GAO X P. Electroactive organic compounds as anode-active materials for solar rechargeable redox flow battery in dual-phase electrolytes. Journal of The Electrochemical Society, 2014, 161(5): A736-A741.

[55] KAGAN C R, MITZI D B, DIMITRAKOPOULOS C D. Organicinorganic hybrid materials as semiconducting channels in thin-film field-effect transistors. Science, 1999, 286(5441): 945-947.

[56] MITZI D B, FEILD C A, HARRISON W T A, et al. Conducting tin halides with a layered organic-based perovskite structure. $\mathrm{Na}$ ture, 1994, 369(6480): 467.

[57] KOJIAMA A, TESHIMA K, SHIRAI Y, et al. Organometal halide perovskites as visible-light sensitizers for photovoltaic cells. Journal of the American Chemical Society, 2009, 131(17): 6050-6051.

[58] CHU Z Y, LI G L, JIANG Z H, et al. Recent progress in high-quality perovskite $\mathrm{CH}_{3} \mathrm{NH}_{3} \mathrm{PbI}_{3}$ single crystal. Journal of Inorganic Materials, 2018, 33(10): 1035-1045.

[59] JIANG Q, CHU Z M, WANG P Y, et al. Planar-structure perovskite solar cells with efficiency beyond $21 \%$. Advanced Materials, 2017, 29(46): 1703852.

[60] JIANG Q, ZHANG L Q, WANG H L, et al. Enhanced electron extraction using $\mathrm{SnO}_{2}$ for high-efficiency planar-structure $\mathrm{HC}\left(\mathrm{NH}_{2}\right)_{2} \mathrm{PbI}_{3}$-based perovskite solar cells. Nature Energy, 2017, 2(1): 16177 .

[61] XIONG L B, GUO Y X, WEN J, et al. Review on the application of $\mathrm{SnO}_{2}$ in perovskite solar cells. Advanced Functional Materials, 2018, 28(35): 1802757.

[62] DJURIŠIĆ A B, LIU F Z, TAM H W, et al. Perovskite solar cells-an overview of critical issues. Progress in Quantum Electronics, 2017, 53: 1-37.

[63] HUANG J, XIANG S H, YU J S, et al. Highly efficient prismatic perovskite solar cells. Energy \& Environmental Science, 2019, 12(3): 929-937.

[64] JUNG E H, JEON N J, PARK E Y, et al. Efficient, stable and scal- able perovskite solar cells using poly (3-hexylthiophene). Nature, 2019, 567(7749): 511.

[65] MUNDHAAS N, YU Z J, BUSH K A, et al. Series resistance measurements of perovskite solar cells using $J_{\mathrm{sc}}-V_{\mathrm{oc}}$ measurements. Solar RRL, 2019, 3(4): 1800378.

[66] SCHMAGER R, GOMARD G, RICHARDS B S, et al. Nanophotonic perovskite layers for enhanced current generation and mitigation of lead in perovskite solar cells. Solar Energy Materials and Solar Cells, 2019, 192: 65-71.

[67] SHIN S S, SUK J H, KANG B J, et al. Energy-level engineering of the electron transporting layer for improving open-circuit voltage in dye and perovskite-based solar cells. Energy \& Environmental Science, 2019, 12(3): 958-964.

[68] XIAO Y Q, WANG C L, KONDAMAREDDY K K, et al. Enhancing the performance of hole-conductor free carbon-based perovskite solar cells through rutile-phase passivation of anatase $\mathrm{TiO}_{2}$ scaffold. Journal of Power Sources, 2019, 422: 138-144.

[69] YANG D B, SANO T S, YAGUCHI Y, et al. Achieving 20\% efficiency for low-temperature-processed inverted perovskite solar cells. Advanced Functional Materials, 2019, 29(12): 1807556.

[70] WANG F Y, ZHANG Y H, YANG M F, et al. Exploring low-temperature processed $a-\mathrm{WO}_{x} / \mathrm{SnO}_{2}$ hybrid electron transporting layer for perovskite solar cells with efficiency $>20.5 \%$. Nano Energy, 2019, 63: 103825

[71] XU X B, LI S H, ZHANG H, et al. A power pack based on organometallic perovskite solar cell and supercapacitor. ACS Nano, 2015, 9(2): 1782-1787.

[72] LIANG J, ZHU G Y, LU Z P, et al. Integrated perovskite solar capacitors with high energy conversion efficiency and fast photocharging rate. Journal of Materials Chemistry A, 2017, 6(5): 2047-2052.

[73] KIM J, LEE S M, HWANG Y H, et al. A highly efficient self-power pack system integrating supercapacitors and photovoltaics with an area-saving monolithic architecture. Journal of Materials Chemistry A, 2017, 5(5): 1906-1912.

[74] LIU R H, LIU C H, FAN S S. A photocapacitor based on organometal halide perovskite and PANI/CNT composites integrated using a CNT bridge. Journal of Materials Chemistry A, 2017, 5(44): $23078-23084$.

[75] LI C, ISLAM M M, MOORE J L, et al. Wearable energy-smart ribbons for synchronous energy harvest and storage. Nature Communications, 2016, 7: 13319.

[76] JIA C M, ZHAO X Y, LAI Y H, et al. Highly flexible, robust, stable and high efficiency perovskite solar cells enabled by van der Waals epitaxy on mica substrate. Nano Energy, 2019, 60: 476-484.

[77] HU Y X, BAI Y, LUO B, et al. A portable and efficient solarrechargeable battery with ultrafast photo-charge/discharge rate. Advanced Energy Materials, 2019, 9(28): 1900872. 